\title{
Congenital pulmonary veins atresia or stenosis
}

INSERM

\section{Source}

INSERM. (1999). Orphanet: an online rare disease and orphan drug data base. Congenital pulmonary veins atresia or stenosis. ORPHA:3188

Congenital pulmonary vein $(\mathrm{PV})$ stenosis or atresia is a rare progressive life-threatening great vessels anomaly characterized by narrowing and obstruction of one or more normally positioned PV at their junction with the left atrium, that usually presents during early infancy with dyspnea, tachypnea, and repeated pulmonary infections, and eventually, when all PV of one lung are affected, results in pulmonary hypertension (PH) and consecutive pulmonary arterial hypertension (PAH) (see this term). It may manifest as an isolated lesion or associated with other cardiac defects such as congenital pulmonary venous return anomaly (see this term) and septal defects. 